\title{
Predicting intervention in renal colic patients after emergency department evaluation
}

\author{
Linda Papa, MD CM, MSc, CCFP, FRCP, FACEP; ${ }^{*}$ Ian G. Stiell, MD, MSc, FRCP; ${ }^{\dagger}$
} George A. Wells, PhD; $;^{\dagger}$ Ian Ball, MD; ${ }^{\dagger}$ Erica Battram, RN, ENCC; ${ }^{\dagger}$ John E. Mahoney, MD, FRCS ${ }^{\S}$

\begin{abstract}
Objectives: There is no set of prospectively validated criteria to identify the emergency department (ED) patients with renal colic who are most likely to eventually have to undergo an intervention. This study prospectively assessed predictors of intervention in this patient population.

Methods: This prospective cohort study included adult patients with renal colic who presented to 2 tertiary care hospital EDs. Patients had an 18-variable data form completed by an emergency physician and a radiological study to confirm urolithiasis. After discharge, patients were followed at 1 and 4 weeks to assess for intervention. The outcome criteria included the patient having had at least 1 of the following procedures performed: extracorporeal shockwave lithotripsy (ESWL), ureteroscopy, percutaneous nephrostomy or open surgery. Data were analyzed using appropriate univariate techniques, and those variables associated with intervention were combined using logistic regression analysis.

Results: Over an 8-month period, 245 patients with confirmed urolithiasis were followed; $20 \%$ (95\% confidence interval [CI] 15\%-25\%) eventually had a procedure to remove their calculi. Three variables were significantly correlated with having a procedure: i) size of calculus $\geq 6 \mathrm{~mm}$ (odds ratio [OR] 10.7, 95\% Cl 4.6-24.8), ii) location of calculus above mid-ureter (OR 6.9, 95\% Cl 3.0-15.9), and iii) Visual Analogue Scale score for pain at discharge from the ED $\geq 2 \mathrm{~cm}(\mathrm{OR} 2.6,95 \% \mathrm{Cl}$ 1.0-6.8). The area under receiver operating characteristic curve was 0.77 (95\% C I 0.70-0.84) $(p<$ 0.001 ). If all variables were present there was a $90 \%$ probability of the patient having an intervention performed within 4 weeks of discharge from the ED. Conversely, if none of the variables were present there was only a $4 \%$ probability of an intervention. Overall, the model had a sensitivity of $92 \%(95 \% \mathrm{Cl} 89 \%-96 \%)$ and a specificity of $63 \%(95 \% \mathrm{Cl} 57 \%-69 \%)$.

Conclusions: This study has identified variables that could potentially be used to identify those renal colic patients who require an intervention after ED evaluation. Future studies will prospectively validate this model.
\end{abstract}

Key words: renal colic; intervention; clinical decision rule; predictor

RÉSUMÉ

Objectifs : II n'existe pas d'ensemble de critères validés prospectivement pour identifier les patients reçus au département d'urgence pour une colique néphrétique qui sont les plus susceptibles

\footnotetext{
*Department of Emergency Medicine, University Of Florida, Gainesville, Fla. tDepartment of Emergency Medicine, University Of Ottawa, Ottawa, Ont. ‡Department of Epidemiology \& Community Medicine, University Of Ottawa, Ottawa, Ont. §Division of Urology, University of Ottawa, University Of Ottawa, Ottawa, Ont.
}

Received: July 26, 2004; final submission: Oct. 27, 2004; accepted: Nov. 22, 2004

This article has been peer reviewed.

Can J Emerg Med 2005;7(2):78-86 
de subir ultérieurement une intervention. La présente étude a fait une évaluation prospective des interventions parmi ces patients.

Méthodes: Cette étude de cohortes prospective incluait les patients adultes atteints de colique néphrétique reçus à deux départements d'urgence d'hôpitaux de soins tertiaires. Un médecin d'urgence remplit un formulaire de données à 18 variables pour les patients et leur fit subir un examen radiologique pour confirmer la présence d'une urolithiase. Après avoir reçu leur congé, les patients furent suivis après une et quatre semaines pour déterminer la nécessité d'effectuer une intervention. Les critères de résultats incluaient la nécessité que le patient ait subi au moins l'une des interventions suivantes: néphrolithotripsie extra-corporelle par ondes de choc, urétéroscopie, néphrostomie percutanée et chirurgie ouverte. Les données furent analysées à l'aide de techniques à une variable appropriées et ces variables associées à des interventions furent combinées grâce à une analyse de régression logistique.

Résultats: Au cours d'une période de huit mois, 245 patients atteints d'urolithiase confirmée furent suivis; $20 \%$ (intervalle de confiance [IC] de $95 \% \quad 15 \%-25 \%$ ) subirent ultérieurement une intervention pour l'extraction de leurs calculs. Trois variables avaient une corrélation significative avec le fait de subir l'intervention : i) la taille du calcul $\geq 6 \mathrm{~mm}$ (rapport de cotes [RC] 10,7, IC $95 \%$ $4,6-24,8)$, ii) la position du calcul dans la partie supérieure de l'uretère (RC 2,6, IC $95 \%$ 3,0-15,9), et iii) un score de douleur à l'échelle visuelle analogue de $\geq 2 \mathrm{~cm}$ lors du congé du département d'urgence (RC 2,6, IC $95 \%$ 1,0-6,8). La région sous la courbe ROC (receiver operating characteristic) était de 0,77 (IC $95 \% 0,70-0,84)(p<0,001)$. Si toutes les variables étaient présentes, il y avait une probabilité à $90 \%$ que le patient subisse une intervention dans les quatre semaines suivant son congé du département d'urgence. À l'inverse, si aucune des variables n'était présente, la probabilité d'une intervention était seulement de $4 \%$. Dans l'ensemble, le modèle présentait une sensibilité de $92 \%$ (IC $95 \% 89 \%-96 \%$ ) et une spécificité de $63 \%$ (IC $95 \% 57 \%-69 \%$ ).

Conclusions : Cette étude a identifié des variables qui pourraient être utilisées pour identifier les patients atteints d'une colique néphrétique nécessitant une intervention après leur évaluation au département d'urgence. Des études ultérieures valideront ce modèle de manière prospective.

\section{Introduction}

Renal colic is a common condition in North America and worldwide and is one of the most common conditions seen in the emergency department (ED)..$^{1-3}$ About $5 \%-15 \%$ of the North American and European populations, ${ }^{2,3} 2 \%-5 \%$ of Asians and $20 \%$ of the people in Saudi Arabia ${ }^{4}$ pass a urinary calculus in their lifetime. Urolithiasis usually develops when a person is between the ages of 20 and 40 years, and these patients will have a $50 \%$ chance of recurrence over 5 years. ${ }^{3,5}$

Recent studies have shown that up to $40 \%$ of patients with urolithiasis have difficulty passing their calculi and often require an intervention. ${ }^{6-9}$ In the US, indirect costs for lost wages from urolithiasis is estimated at US $\$ 139$ million annually. ${ }^{10}$ Due to the rising costs of hospitalization, lost wages and patient disability, the current trend is for earlier intervention. ${ }^{11-13}$ However, referral for intervention in these patients is not standardized. ${ }^{13,14}$

Follow-up with a urologist is often given indiscriminately, and appointments are delayed because of the large volume of undifferentiated referrals. Patients with persistent or recurrent pain who are waiting for procedures are repeatedly seen in the ED; this contributes to an increased risk of complications for the patients, and increased health care costs and ED patient volumes. ${ }^{13-16}$ If intervention is unlikely after the initial ED evaluation, patients could be referred for further assessment and follow-up to their family physician rather than to a urologist. A valid decision tool to identify on initial ED visit those renal colic patients who will likely eventually undergo a procedure would allow emergency physicians to prioritize and standardize referrals for urological treatment.

The goal of this study was to identify clinical factors in the ED that are sensitive and specific in predicting which patients with urolithiasis will likely require an intervention after leaving the ED.

\section{Methods}

\section{Study setting and population}

We conducted a prospective observational cohort study, and assessed consecutive adult patients with renal colic presenting to 2 university teaching hospital EDs over an 8month period. We followed the methodological standards for development of clinical decision rules..$^{1718}$ The Ottawa 
Hospital has 2 sites with access to diagnostic imaging and urologists 24 hours a day, and has a combined annual ED census of 120000 patients. Eligibility was based upon the patients' having confirmed ureteral calculi and being available for telephone follow-up. We excluded patients if they had acutely unstable vital signs, were already enrolled, were pregnant or would be unavailable for follow-up. The research ethics committees of the 2 study sites of the Ottawa Hospital approved the protocol.

\section{Standardized patient assessment}

All physician assessors were certified in emergency medicine and trained, via a 1-hour teaching session, to evaluate the patients using an 18-variable data form. The potential predictor variables included clinical findings from the history and physical examination, and radiological findings. Patients were selected based on data from the literature and the clinical experience of emergency physicians (EPs) and urologists from the 2 institutions.

Findings from the clinical examination were recorded on data collection forms by the treating physician, prior to radiography. Patients were asked to rate their pain on a continuous 10-cm Visual Analogue Scale (VAS), both at the start of their clinical examination and just before discharge. The EP treated the patient in the ED as per his or her usual practice; the majority of suspected renal colic patients underwent diagnostic imaging (81\%), urine dip or urinalysis (95\%) and assessment of serum creatinine (90\%). Additionally, patients were treated with intravenous narcotics and NSAIDs, when not contraindicated. When feasible, a subset of patients (10\%) was assessed by a second physician to determine interobserver agreement for clinical signs and symptoms.

Because not all patients with suspected urolithiasis routinely undergo imaging at the study sites, we could not ethically mandate universal imaging for all eligible patients; therefore, we followed a small subset of patients who did not undergo imaging, to determine the intervention rate in this group.

Staff radiologists interpreted the results of all imaging studies (mostly intravenous pyelograms [IVPs]) and were blinded to the contents of the data collection sheet. The reliability of the radiography interpretations was assessed by having $10 \%$ of randomly selected IVPs reviewed by a urologist who was unaware of the first interpretation. Radiologists and urologists showed a $90 \%$ agreement in their interpretations of the abnormal IVPs.

\section{Outcome measures and assessment}

The primary outcome was urological intervention within
28 days of initial ED presentation. Urological intervention was defined as any of the 4 following procedures being performed to relieve the obstruction from a urinary calculus: 1) ureteroscopy, 2) percutaneous nephrostomy, 3) extracorporeal shockwave lithotripsy (ESWL), or 4) open surgery. To verify the uniformity of practice patterns of the urologists who were treating the study patients, we conducted a formal survey of all urologists in the Ottawa area. Ten of eleven $(91 \%)$ urologists completed the survey. There was $80 \%$ agreement among the urologists on the clinically important criteria for intervention. These criteria included fever, severity of obstruction, prolonged pain, compromise of renal function, size of calculus and a solitary kidney.

To assess outcome, structured telephone interviews were carried out by a registered nurse at 1 and 4 weeks after the enrolled patient's discharge. All patients with urolithiasis that had been confirmed by imaging were interviewed after discharge. Patients were asked about persistence of pain, urinary symptoms, revisits to a physician or the ED, and interventions subsequently performed on them. The registered nurse was unaware of the patient's status for the individual clinical predictor variables. Those patients reporting an intervention or a return visit to the ED had their medical charts reviewed for admission notes and operative reports. A 4-week follow-up period was selected based on pilot data that revealed that, at our 2 sites, most urological procedures for renal colic were performed within 4 weeks.

\section{Data analysis}

We measured interobserver agreement for selected variables by calculating the kappa coefficient, the proportion of potential agreement beyond chance. The strength of association between the clinical predictor variables and outcomes of intervention was tested using univariate analysis: for nominal data, the chi-squared test with continuity correction; for ordinal variables, the Mann-Whitney $U$ test; and for continuous variables, the unpaired 2-tailed $t$ test, using pooled or separate variance estimates as appropriate. Intervention was analyzed as a dichotomous outcome. This process aided in the selection of the best variables for the logistic regression analysis. With those variables found to be both reliable $(\kappa>0.6)$ and strongly associated with the outcome measure $(p<0.05)$ in the univariate analysis further consideration used backward stepwise logistic regression to obtain odds ratios (ORs) with $95 \%$ confidence intervals (CIs). The Hosmer and Lemeshow Goodness-of-Fit test statistic was used to assesses the significance of the logistic regression model so that a level $>0.05$ suggests a good fit of the data. 
Additionally, we compared the classification of each patient with their actual status for the primary outcome allowing an estimate, with 95\% CI of the sensitivity and specificity of the rule. All analyses were performed using the statistical software package SPSS, version 10.0.5.

The a priori sample size was estimated to be $250 \mathrm{pa}$ tients, based upon the desired precision of $100 \%$ sensitivity for requiring a urological intervention with $95 \%$ CI of 91\%-100\%. This CI was selected by the investigators at a planning consensus conference. Time frame of accrual based on an earlier chart review was estimated at 6 months.

\section{Results}

Between January 1999, and September 1999, 437 patients with renal colic were assessed for urolithiasis in 1 of the 2 ED study sites. Of these, 326 patients were found through radiographic studies to have urolithiasis and were eligible for the study. Seventy-five percent (245) of these patients were enrolled and had complete assessment of the primary outcome measure, urological intervention, subsequent to discharge from the ED and formed our final study sample (Table 1). Of the 81 patients who were not included in the final study sample, 49 were eligible but had not been enrolled by the treating physicians, 5 declined to participate or had a language barrier and 27 would not have been available by telephone for the 4-week follow-up period (Fig. 1). Enrolled patients were similar to those not enrolled in their distribution of age, gender, time spent in the $\mathrm{ED}$, return visits, previous history of renal colic and clinical variables measured.

Of the 245 renal colic patients in the final sample, 50 (20\%) underwent urological intervention. Eighteen were admitted from the ED for an intervention, and 32 had their intervention after being discharged from the ED. The urological interventions performed on these patients included ESWL (12 patients), ureteroscopy (27), percutaneous nephrostomy (10), open surgery (1), or more than one procedure (7). In reviewing the operative reports of the patients who underwent an intervention, the reasons cited by the urologists in the charts for performing a procedure on the urinary calculi included: calculus size (32\%), development of an infected calculus (19\%), severe obstruction (19), location of calculus in the upper ureter (14\%), acute renal failure (10\%) and persistent pain $(6 \%)$.

We also followed a subset of 30 patients for whom imaging was not performed while they were in the ED, to determine the intervention rate in this group. We found that $13 \%$ had undergone a urological procedure. Presence of urolithiasis in this group was assessed through outpatient imaging or self reported "passing" of a calculus.

Table 2 shows the association between the 18 predictor variables and urological intervention, as determined by univariate analyses, as well as the kappa coefficients of the selected variables. Only those clinical variables obtained prospectively were used in the univariate analysis. Overall, we assessed 18 primary predictor variables as well as another 8 created by cut-points. Those variables having a statistically significant $(p<0.05)$ association with intervention included patient's VAS pain score at discharge, location of the calculus along urinary system, and size of the calculus. Interobserver agreement for both size and lo-

Table 1. Characteristics of the 245 patients who presented to the emergency department (ED) with renal colic and were subsequently enrolled in the study

\begin{tabular}{|c|c|}
\hline Characteristics & $\begin{array}{l}\text { No. }(\text { and } \%) * \\
\text { of patients* }\end{array}$ \\
\hline Mean age, yr (and SD) & $45(14)$ \\
\hline Age range, yr & $18-87$ \\
\hline Male gender & $162(66)$ \\
\hline Previous history of renal colic & $127(52)$ \\
\hline Referred to urologist by EP & $198(81)$ \\
\hline ED length of stay, + min (and SD) & $356(185)$ \\
\hline Admitted & $45(18)$ \\
\hline Revisited ED within 4-week study period & $72(29)$ \\
\hline \multicolumn{2}{|l|}{ Pain assessment } \\
\hline $\begin{array}{l}\text { Duration of pain prior to arrival, } \mathrm{hr} \\
\text { (and SD) }\end{array}$ & $5.1(5.6)$ \\
\hline Mean VAS score $\ddagger$ on arrival, cm (and SD) & $7.2(2.9)$ \\
\hline $\begin{array}{l}\text { Mean VAS score } ¥ \text { on discharge, } \mathrm{cm} \\
\text { (and SD) }\end{array}$ & $1.0(1.8)$ \\
\hline \multicolumn{2}{|l|}{ Investigations performed during ED visit } \\
\hline Imaging & $245(100)$ \\
\hline Intravenous pyelogram & $216(88)$ \\
\hline Plain film & $42(17)$ \\
\hline Ultrasound & $16(7)$ \\
\hline CT scan & $5(2)$ \\
\hline \multicolumn{2}{|l|}{ Positive lab results, total no. of patients tested } \\
\hline Hematuria on urine dipstick, 216 & $192(89)$ \\
\hline Pyuria on urine dipstick, 216 & $41(19)$ \\
\hline Mean serum creatinine, 213 & $91(41)$ \\
\hline $\begin{array}{l}\text { Total no. of study patients who } \\
\text { subsequently had to have an Intervention }\end{array}$ & $50(20)$ \\
\hline \multicolumn{2}{|l|}{ Type of intervention } \\
\hline Extracorporeal shockwave lithotripsy & $12(5)$ \\
\hline Ureteroscopy & $27(11)$ \\
\hline Percutaneous nephrostomy & $10(4)$ \\
\hline Open surgery & $1(0.4)$ \\
\hline More than one procedure & $7(3)$ \\
\hline \multicolumn{2}{|c|}{$\begin{array}{l}\mathrm{CT}=\text { computed tomography; } \mathrm{EP}=\text { emergency physician; } \mathrm{SD}=\text { standard deviation } \\
\text { *Unless otherwise indicated. } \\
\text { tFrom registration to discharge. } \\
\text { †Continuous } 10-\mathrm{cm} \text { VAS [Visual Analogue Scale]. }\end{array}$} \\
\hline
\end{tabular}


cation of the calculus on radiography showed a kappa coefficient of $\kappa>0.88$ and $\kappa>0.96$, respectively.

Using these clinical variables in a stepwise backward logistic regression analysis yielded a model of 3 variables (Table 3) with good overall accuracy for discriminating cases that require a urological intervention. The area under receiver operating characteristic (ROC) curve was 0.77 (95\% CI $0.70-0.84 ; p<0.001$ ) with the Hosmer and Lemeshow Goodness-of-Fit, $p=0.10$ (Fig. 2). The ORs for each variable, adjusted for the other variables in the model, are displayed with 95\% CIs in Figure 3. In comparison, the area under ROC curve for actual urological referrals given was 0.43 (95\% CI 0.35-0.52; $p=0.14$ ).

A patient not satisfying any of the variables in the model would have a probability of having an intervention of $4 \%$. If all variables in the model were satisfied, then the patient would have a $90 \%$ probability of having an intervention. Overall, if any one variable is present, then the sensitivity of the model is $92 \%$ (95\% CI 89\%-96\%) and the specificity is $63 \%$ (95\% CI 57\%-69\%).

The proportion of renal colic patients being referred to a urologist was $81 \%$ at our institution. Of those who were referred only $22 \%$ had an intervention. Of the $19 \%$ of renal colic patients who were not referred to a urologist, $12 \%$ eventually did require an intervention.

\section{Discussion}

Currently, there are no guidelines for EPs to determine those renal colic patients who will likely require an intervention after initial ED evaluation. Urological follow-up for definitive treatment after ED discharge is not standardized because of the lack of validated criteria to prioritize patients. ${ }^{13-15}$

Our prospectively derived model of 3 simple variables - a ureteral calculus measuring $6 \mathrm{~mm}$ or more, a calculus situated above the mid-ureter, or residual pain at discharge - predicted a high likelihood of urological intervention. If at least 1 of the variables was present, the model's sensitivity and specificity were $92 \%$ and $63 \%$ respectively. In contrast, our EP referral practice was only $88 \%$ sensitive $(88 \%$ of patients who required intervention were referred to a urologist) and $21 \%$ specific. Overall, using the derived criteria only $49 \%$ of patients would have been given an urgent referral (instead of $81 \%$ ) to a urologist, and definitive care would have been provided earlier to the $12 \%$ who should have been referred.

The important question of predicting intervention in renal colic has, for decades, only been addressed through retrospective studies showing that persistence of pain, size of calculus, location along the ureter, impaired renal function, obstruction and signs of infection are important factors influencing intervention. ${ }^{8,15,19-23}$ Our predictive variables for intervention are remarkably similar to other studies $^{8,12,15,23-25}$ and demonstrate that our sample of renal colic patients is comparable to other populations described in the literature. ${ }^{14,26-28}$ Although not all patients had an intervention or were enrolled in the study, we

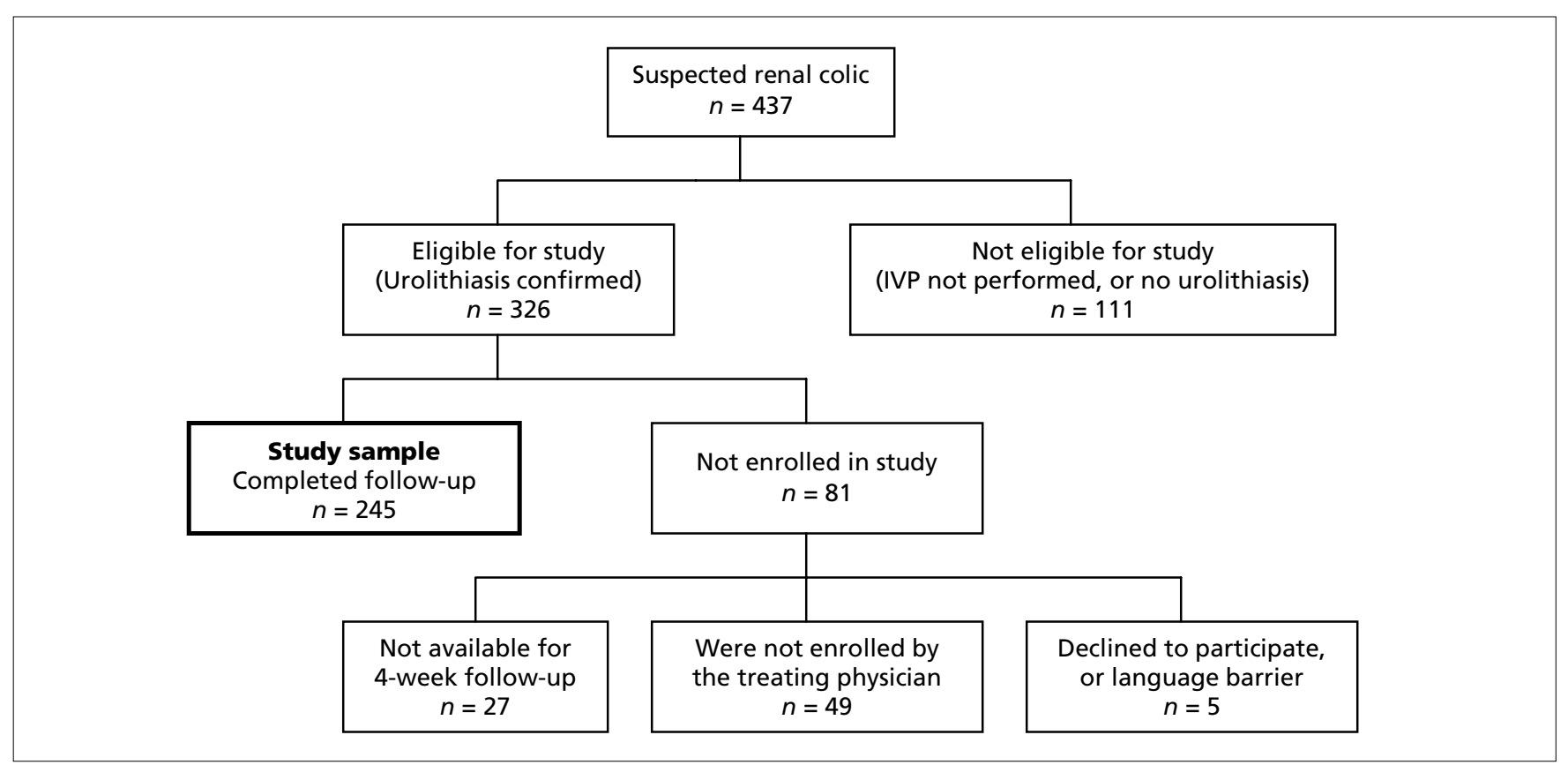

Fig. 1. Cohort of patients presenting with suspected renal colic. 
found no systematic difference between enrolled and excluded patients.

Surgical intervention has changed with the development of new techniques such as ESWL and minimally invasive endoscopic techniques such as ureteroscopy, and are associated with very low morbidity. ${ }^{29}$ The majority of patients

\begin{tabular}{|c|c|c|c|c|}
\hline Variables & $\begin{array}{l}\text { Intervention } \\
\quad(n=50)\end{array}$ & $\begin{array}{c}\text { No } \\
\text { intervention } \\
(n=195)\end{array}$ & $\begin{array}{c}p \\
\text { value }\end{array}$ & Kappa \\
\hline Age, yr (mean and SD) & $48(18.0)$ & $44(12.5)$ & 0.32 & \\
\hline Male gender, $\%$ & 66 & 66 & 1.00 & \\
\hline History of renal colic, \% & 63 & 49 & 0.11 & \\
\hline \multicolumn{5}{|l|}{ Signs and symptoms } \\
\hline Temperature,${ }^{\circ} \mathrm{C}$ (and SD) & $36.3(1.3)$ & $36.1(0.7)$ & 0.29 & \\
\hline Vomiting, $\%$ & 49 & 44 & 0.63 & 0.88 \\
\hline Dysuria, $\%$ & 14 & 17 & 0.65 & 0.76 \\
\hline Urinary frequency, \% & 13 & 25 & 0.11 & 0.76 \\
\hline Abdominal tenderness, $\%$ & 36 & 48 & 0.15 & 0.92 \\
\hline Rebound tenderness, \% & 3 & 2 & 1.00 & 0.76 \\
\hline CVA tenderness, $\%$ & 62 & 58 & 0.63 & 0.72 \\
\hline $\begin{array}{l}\text { Hours of pain prior to ED visit } \\
\text { (and SD) }\end{array}$ & $5.2(7.3)$ & $5.0(5.1)$ & 0.87 & \\
\hline \multicolumn{5}{|l|}{ VAS scores* } \\
\hline Upon arrival, cm (and SD) & $7.5(2.9)$ & $7.1(2.9)$ & 0.39 & \\
\hline At discharge, $\mathrm{cm}$ (and SD) & $2.0(2.4)$ & $0.8(1.5)$ & 0.03 & \\
\hline$\geq 0 \mathrm{~cm}, \%$ & 90 & 78 & 0.07 & \\
\hline$\geq 1 \mathrm{~cm}, \%$ & 84 & 66 & 0.02 & \\
\hline$\geq 2 \mathrm{~cm}, \%$ & 28 & 13 & 0.02 & \\
\hline$\geq 3 \mathrm{~cm}, \%$ & 24 & 11 & 0.04 & \\
\hline \multicolumn{5}{|l|}{ Laboratory I Imaging results } \\
\hline Hematuria urine dip (median) & Large & Large & 0.37 & \\
\hline Pyuria on urine dip (median) & None & None & 0.14 & \\
\hline $\begin{array}{l}\text { Serum creatinine, } \mu \mathrm{mol} / \mathrm{L} \\
\quad \text { (and SD) }\end{array}$ & $105(77.7)$ & $87.6(24.2)$ & 0.15 & \\
\hline $\begin{array}{l}\text { Calculus location above mid- } \\
\text { ureter, \% }\end{array}$ & 76 & 25 & $<0.001$ & 0.96 \\
\hline Size of calculus, mm (and SD) & $7.6(5.7)$ & $3.5(2.0)$ & $<0.001$ & 0.88 \\
\hline$\geq 5 \mathrm{~mm}, \%$ & 80 & 25 & $<0.001$ & \\
\hline$\geq 6 \mathrm{~mm}, \%$ & 60 & 8 & $<0.001$ & \\
\hline$\geq 7 \mathrm{~mm}, \%$ & 48 & 5 & $<0.001$ & \\
\hline$\geq 8 \mathrm{~mm}, \%$ & 38 & 2 & $<0.001$ & \\
\hline
\end{tabular}

Table 3. Logistic regression analysis to predict the need for intervention for patients with confirmed urolithiasis after their discharge from the emergency department

\begin{tabular}{|c|c|c|c|c|c|c|}
\hline Variable & $\beta$ & SE & $\begin{array}{c}\text { Wald } \\
\text { test }\end{array}$ & $p$ value & OR & $95 \% \mathrm{Cl}$ \\
\hline VAS score* at discharge $\geq 2 \mathrm{~cm}$ & 0.9 & 0.5 & 3.7 & 0.056 & 2.6 & $1.0-6.8$ \\
\hline Size of calculus $\geq 6 \mathrm{~mm}$ & 2.4 & 0.4 & 30.4 & $<0.001$ & 10.7 & $4.6-24.8$ \\
\hline Calculus above mid-ureter & 1.9 & 0.4 & 21.0 & $<0.001$ & 6.9 & $3.0-15.8$ \\
\hline
\end{tabular}


in our study who had an intervention underwent ureteroscopy and ESWL in accordance with the 1997 recommendations of a urology task force on urolithiasis, ${ }^{12}$ which demonstrates the compliance of our urologists with North American standards.

Prompt referral to a urologist is important for many reasons. Complications from an intervention for ureteral obstruction are much higher when symptoms exceed 4 weeks' duration. ${ }^{15,16}$ Irreversible renal damage can occur with urinary obstruction that impairs renal function for over 2 weeks. ${ }^{5,29-31}$ In the US, the societal burden and indirect costs for lost wages from urolithiasis are estimated to be US\$139 million annually. ${ }^{10}$

The strength of our study is that data were gathered prospectively using sound methodology. ${ }^{17}$ Clinical predictor variables were easy to apply and prospectively identified in a blinded fashion while being tested for interobserver agreement. We clearly defined a clinically important outcome and formally surveyed the participating urologists to ensure uniformity of practice patterns prior to the study. These methods have been used in other high calibre decision rule studies. ${ }^{32-35}$

Our study also has potential limitations. The outcome "urological intervention" can vary among urologists in different geographic areas and may be influenced by independent patient factors such as associated ureteral pathology, patient occupation and patient preference. Despite this, studies conducted in different geographic locations have

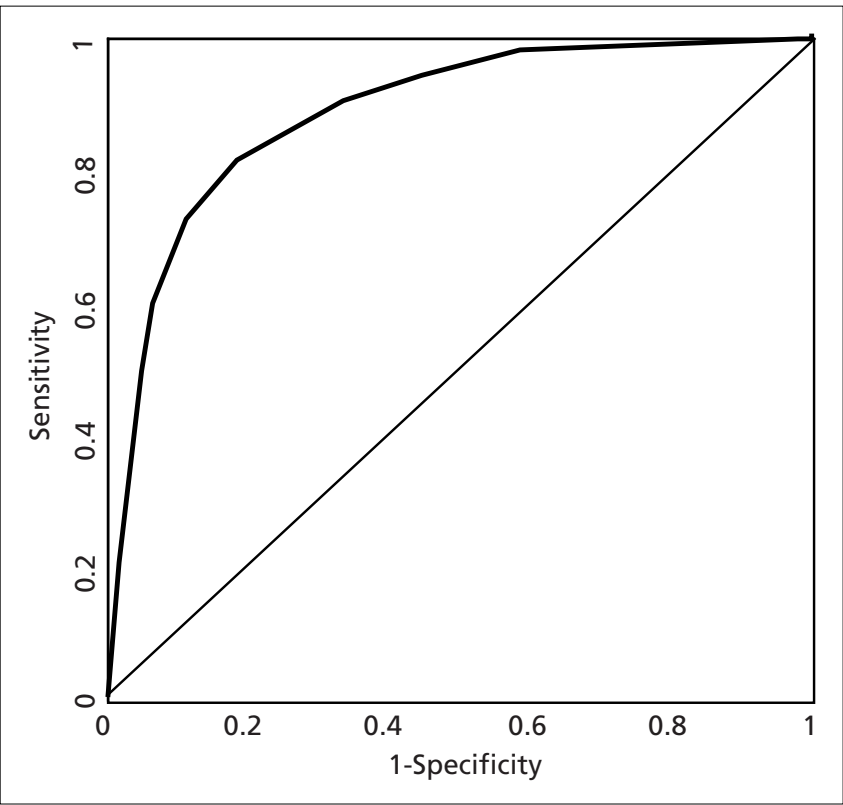

Fig. 2. ROC [receiver operating characteristic] curve of the classification performance of the logistic regression model for predicting intervention. obtained similar results to our study. $8,15,23,25$

At the time of this study, IVP was the imaging study of choice at our institution because of its availability and ability to assess renal function and obstruction. Given that CT scanning is becoming the imaging modality of choice for diagnosing urolithiasis, future validation of this decision rule should use CT scan. Data from CT imaging techniques would likely improve the estimation of calculus size and location, particularly with very small calculi. ${ }^{36-38} \mathrm{Nev}$ ertheless, IVP was once the gold standard and is well known to be accurate in diagnosing urolithiasis. .6,39-41 $^{2}$

For this derivation study, the investigators determined at a planning consensus conference that a $95 \%$ CI of $91 \%-100 \%$ around a sensitivity of $100 \%$ was adequate for a decision rule to predict the need for urological intervention. During the validation phase we will formally survey EPs and urologists to assess what an acceptable sensitivity would be for the rule. An economic analysis to assess cost should also be part of the validation phase.

Of the 3 variables in the final model, calculus size $\geq 6 \mathrm{~mm}$ and location above the mid-ureter were the most statistically robust. Residual pain at discharge as an independent predictor of intervention is novel and will require further validation. This variable may indicate disease severity, suggesting that pain may be more difficult to control in those with calculi that are difficult to pass. Our EPs followed a common analgesic regimen to control renal colic pain: a combination of an NSAID and titration of an intravenous narcotic until pain control was achieved. All patients were required to ambulate independently before being discharged from the ED. Over $60 \%$ of our patients left in a complete pain-free state.

\section{Summary}

In this study, predictors of urological intervention for pa-

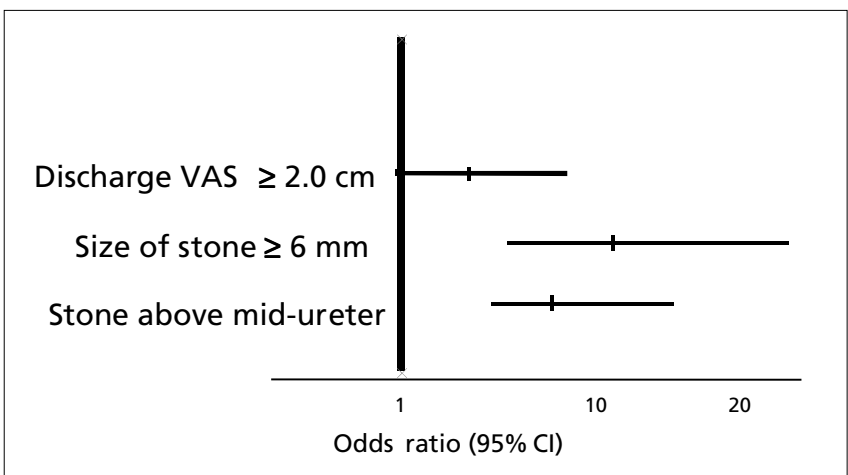

Fig. 3. Odds ratio with $95 \%$ confidence intervals (Cls) for predictor variables in the logistic regression analysis. VAS = Visual Analogue Scale. 
tients presenting to the ED with renal colic include: 1) calculus size of $6 \mathrm{~mm}$ or larger, 2) calculus above the midureter, and 3) residual pain at discharge as measured with a VAS score of $\geq 2 \mathrm{~cm}$. The potential implications of a valid decision tool in this patient population are optimization and standardization of care, reduction of return ED visits and, ultimately, reduction in complications from delayed procedures. ${ }^{13-16}$ Additionally, health care costs could be impacted by reduced complications, fewer ED visits and unnecessary referrals. Future studies to prospectively validate this model in another cohort of patients are important before we would advocate widespread clinical use of these predictors.

\section{Competing interests: None declared.}

\section{References}

1. Press SM, Smith AD. Incidence of negative hematuria in patients with acute urinary lithiasis presenting to the emergency room with flank pain. Urology 1995;45(5):753-7.

2. Elton TJ, Roth CS, Berquist TH, Silverstein MD. A clinical prediction rule for the diagnosis of ureteral calculi in emergency departments. J Gen Intern Med 1993;8(2):57-62.

3. Stewart C. Nephrolithiasis. Emerg Med Clin North Am 1988; 6(3):617-30.

4. Pak CY. Kidney stones. Lancet 1998;351:1797-801.

5. Rhea JT, DeLuca SA, Toombs BD. Evaluation of a sequence of diagnostic tests using the workup of ureteral stone as a model. Med Care 1982;20(8):843-8.

6. Dalrymple NC, Verga M, Anderson KR, Bove P, Covey AM, Rosenfield AT, et al. The value of unenhanced helical computerized tomography in the management of acute flank pain. J Urol 1998;159(3):735-40.

7. Chia SJ, Lau W, Tan PK, Consigliere D, Li MK, Low CH. Ureteric colic: value of initial investigations and the outcome. Ann Acad Med Singapore 1995;24(3):366-9.

8. Prina LD, Rancatore E, Secic M, Weber RE. Comparison of stone size and response to analgesic treatment in predicting outcome of patients with renal colic. Eur J Emerg Med 2002; 9(2):135-9.

9. Kobayashi T, Nishizawa K, Watanabe J, Ogura K. Clinical characteristics of ureteral calculi detected by nonenhanced computerized tomography after unclear results of plain radiography and ultrasonography. J Urol 2003;170(3):799-802.

10. Clark JY, Thompson IM, Optenberg SA. Economic impact of urolithiasis in the United States. J Urology 1995;154:2020-4.

11. LeRoy AJ. Diagnosis and treatment of nephrolithiasis: current perspectives. AJR Am J Roentgenol 1994;163(6):1309-13.
12. Segura JW, Preminger GM, Assimos DG, Dretler SP, Kahn RI, Lingeman JE, Macaluso JN Jr. Ureteral Stones Clinical Guidelines Panel summary report on the management of ureteral calculi. The American Urological Association. J Urol 1997; 158(5):1915-21.

13. Holman CD, Wisniewski ZS, Semmens JB, Bass AJ. Changing treatments for primary urolithiasis: impact on services and renal preservation in 16,679 patients in Western Australia. BJU Int 2002;90(1):7-15.

14. Tasso SR, Shields CP, Rosenberg CR, Sixsmith DM, Pang DS. Effectiveness of selective use of intravenous pyelography in patients presenting to the emergency department with ureteral colic. Acad Emerg Med 1997;4(8):780-4.

15. Hubner WA, Irby P, Stoller ML. Natural history and current concepts for the treatment of small ureteral calculi. Eur Urol 1993;24(2):172-6.

16. Irving SO, Calleja R, Lee F, Bullock KN, Wraight P, Doble A. Is the conservative management of ureteric calculi of $>4 \mathrm{~mm}$ safe? BJU Int 2000;85(6):637-40.

17. Laupacis A, Sekar N, Stiell IG. Clinical prediction rules. A review and suggested modifications of methodological standards. JAMA 1997;277(6):488-94.

18. Stiell IG, Wells GA. Methodologic standards for the development of clinical decision rules in emergency medicine. Ann Emerg Med 1999;33(4):437-47.

19. Jewett MA, Bombardier C, Menchions CW. Comparative costs of the various strategies of urinary stone disease management. Urology 1995;46(3 Suppl A):15-22.

20. Ohkawa M, Tokunaga S, Nakashima T, Yamaguchi K, Orito M, Hisazumi H. Spontaneous passage of upper urinary tract calculi in relation to composition. Urol Int 1993;50(3):153-8.

21. Ibrahim AI, Shetty SD, Awad RM, Patel KP. Prognostic factors in the conservative treatment of ureteric stones. Br J Urol 1991;67(4):358-61.

22. Ueno A, Kawamura T, Ogawa A, Takayasu H. Relation of spontaneous passage of ureteral calculi to size. Urology 1977;10(6):544-6.

23. Fielding JR, Silverman SG, Samuel S, Zou KH, Loughlin KR. Unenhanced helical CT of ureteral stones: a replacement for excretory urography in planning treatment. AJR Am J Roentgenol 1998;171(4):1051-3.

24. Morris SB, Hampson SJ, Gordon EM, Shearer RJ, Woodhouse CR. Should all patients with ureteric colic be admitted? Ann R Coll Surg Engl 1995;77(6):450-2.

25. German I, Lantsberg S, Crystal P, Assali M, Rachinsky I, Kaneti $\mathrm{J}$, et al. Non contrast computerized tomography and dynamic renal scintigraphy in the evaluation of patients with renal colic: Are both necessary? Eur Urol 2002;42(2):188-91.

26. Wrenn K. Emergency intravenous pyelography in the setting of possible renal colic: Is it indicated? Ann Emerg Med 1995; 26(3):304-7. 
27. Haddad MC, Sharif HS, Shahed MS, Mutaiery MA, Samihan AM, Sammak BM, et al. Renal colic: diagnosis and outcome. Radiology 1992;184(1):83-8.

28. Walsh PC, Retik AB, Vaughn ED, Wein AJ, editors. Campbell's Urology, 7th ed. Philadelphia: Saunders; 1998.

29. Holm-Nielsen A, Jorgensen T, Mogensen P, Fogh J. The prognostic value of probe renography in ureteric stone obstruction. Br J Urol 1981;53(6):504-7.

30. Chen MYM, Zagoria RJ, Dyer RB. Radiologic findings in acute urinary tract obstruction. J Emerg Med 1997;15(3):339-43.

31. Katul MJ, Wax SH. Evaluation of renal function during experimental hydronephrosis by means of the radioisotope renogram. Surg Gynecol Obstet 1968;126(3):563-71.

32. Stiell IG, Greenberg GH, McKnight RD, Nair RC, McDowell I, Worthington JR. A study to develop clinical decision rules for the use of radiography in acute ankle injuries. Ann Emerg Med 1992;21(4):384-90.

33. Stiell IG, Wells GA, Vandemheen KL, Clement CM, Lesiuk H, DeMaio V, et al. The Canadian C-spine rule for radiography in alert and stable trauma patients. JAMA 2001;286(15):1841-8.

34. Stiell IG, Wells GA, Vandemheen K, Clement CM, Lesiuk H, Laupacis A, et al. The Canadian CT Head Rule for patients with minor head injury. Lancet 2001;357:1391-6.

35. Stiell IG, Clement CM, McKnight RD, Brison R, Schull MJ, Rowe $\mathrm{BH}$, et al. The Canadian $\mathrm{C}$-spine rule versus the NEXUS low-risk criteria in patients with trauma. N Engl J Med 2003; 349(26):2510-8.

36. Miller OF, Rineer SK, Reichard SR, Buckley RG, Donovan MS, Graham IR, et al. Prospective comparison of unenhanced spiral computed tomography and intravenous urogram in the evaluation of acute flank pain. Urology 1998;52(6):982-7.

37. Niall O, Russell J, MacGregor R, Duncan H, Mullins J. A comparison of noncontrast computerized tomography with excretory urography in the assessment of acute flank pain. J Urol 1999;161(2):5347.

38. Boulay I, Holtz P, Foley WD, White B, Begun FP. Ureteral calculi: diagnostic efficacy of helical CT and implications for treatment of patients. AJR Am J Roentgenol 1999;172(6):1485-90.

39. Collie DA, Paul AB, Wild SR. The diagnostic yield of intravenous urography: a demographic study. Br J Urol 1994;73(6):603-6.

40. Juul N, Brons J, Torp-Pedersen S, Fredfeldt KE. Ultrasound versus intravenous urography in the initial evaluation of patients with suspected obstructing urinary calculi. Scand J Urol Nephrol Suppl 1991;137:45-7.

41. Mendelson RM, Arnold-Reed DE, Kuan M, Wedderburn AW, Anderson JE, Sweetman G, et al. Renal colic: a prospective evaluation of non-enhanced spiral CT versus intravenous pyelography. Australas Radiol 2003;47(1):22-8.

Correspondence to: Dr. Linda Papa, Department of Emergency Medicine, University of Florida, 1329 SW 16th St., Ste. 2204, Gainesville FL 32608; 352 265-5911, fax 352 265-5606, lpstat@aol.com 